\title{
ESCAVANDO SABERES: A ANÁLISE ARQUEOLÓGICA COMO ESTRATÉGIA PARA UMA EDUCAÇÃO AMBIENTAL PÓS- MODERNA
}

Adalberto Ferdnando Inocêncio ${ }^{1}$

Rosana Figueiredo Salvi ${ }^{2}$

Resumo: O presente artigo visa trazer um recorte analítico que compôs uma dissertação de mestrado que consistiu em uma investigação dos discursos anunciados por professores do município de Maringá-PR a respeito de EA e alguns de seus desdobramentos. Para isso, contou, no âmbito metodológico, com a entrevista estruturada. Os focos apresentados são analisados com base nas teorizações do filósofo francês Michel Foucault, mais precisamente considerando seu primeiro domínio - o arqueológico. Nota-se a prevalência de direcionamentos de discursos que se forjaram na modernidade, sendo que, quando confrontados pela crise ambiental contemporânea tais discursos se imiscuem em posicionamentos políticos não nítidos.

Palavras-chave: Método Arqueológico; Crise Ambiental; Discursos.

${ }^{1}$ Universidade Estadual de Londrina. E-mail: afinocencio88@gmail.com

2 Universidade Estadual de Londrina. E-mail: salvi@uel.br

Revbea, São Paulo, V. 12, № 4: 165-179, 2017. revista brasileira educação ambiental 


\section{Introdução}

Este artigo é proveniente de um recorte analítico que compôs uma pesquisa mais ampla de dissertação de mestrado cuja preocupação central foi investigar formações discursivas acerca dos saberes ambientais e científicos manifestos nos discursos de nove professores de Ciências de escolas (públicas e privadas) de distintas regiões da cidade de Maringá - PR (referidos como P1, $\mathrm{P} 2$, e assim por diante). Para isso, realizou-se um caminho problematizando os percursos da modernidade e pós-modernidade trazendo o crivo analítico das teorizações do filósofo francês Michel Foucault para o exame dos discursos dos docentes entrevistados. O interesse principal residiu na observação de práticas e abordagens em Educação Ambiental (EA) subsidiada pelos discursos manifestos por esses docentes que são inerentes a este percurso mencionado.

A escolha deste debate se fez devido ao momento histórico que se abriu na segunda metade do século XX. Este contempla debates sobre a transição para outra episteme científica, os problemas da delimitação do que se entende por ciência e por método e a chamada crise ambiental que se torna pauta de inúmeras discussões atuais, servindo de mote para inúmeras práticas que passam a figurar os debates educacionais mais recentes. $O$ uso do termo em destaque é aqui empregado no sentido foucaultiano (2007, p. 69), para quem se trata de "blocos de constituição do saber ocidental", o que implica assumir que existem descontinuidades na história, naquilo que se pensa e também no que se diz e se faz circular, o que acaba por culminar no "fato de que em alguns anos, por vezes, uma cultura deixa de pensar como fizera até então e se põe a pensar outra coisa e de outro modo".

Ao mesmo tempo, as décadas finais deste século e, principalmente o início dos anos 1990, assinalaram um momento de ampla circulação no número de iniciativas que promoveram a difusão de trabalhos - dissertações, teses, artigos e monografias - sobre EA no cenário brasileiro, além da significativa ramificação qualitativa que delimita o referencial teórico do qual parte e as orientações práticas decorrentes - EA crítica, EA emancipatória, EA para o desenvolvimento sustentável, para ficar nesses exemplos - haja vista o acontecimento da Conferência das Nações Unidas para o Meio Ambiente e Desenvolvimento que ocorreu no Rio de Janeiro em 1992 (REIGOTA, 1998), a qual foi palco de iniciativas mais acaloradas sobre o tema no cenário nacional.

Doravante, a necessidade de investigações bem como de proposições investigativas em EA orientadas por caminhos até então pouco trilhados, que se caracterizam mais por abordagens inventivas do que reprodutivas, tem sido uma condição defendida por alguns autores nos últimos anos, visibilizando um caráter "antropofágico" de pesquisas (BARCELOS, 2004; BARCELOS; SILVA, 2007; REIGOTA, 2002). Admite-se aqui a escolha do percurso arqueológico como potencial percurso antropofágico, uma vez que tal domínio tem sido pouquíssimo empregado nas investigações em EA. 
Esta necessidade de se assumir uma investigação que levou em conta o domínio ${ }^{3}$ ser-saber, foi entendida frente à proximidade ao problema de pesquisa, como o caminho mais profícuo para esta investigação, haja vista que Foucault (2011, p. 44) "usa saberes no sentido de teorias sistemáticas, que se manifestam por meio de discursos científicos tidos por verdadeiros, positivos e, por isso, aceitos e tomados em toda a sua positividade". Em consonância ao trabalho de Maritza Maldonado (2001, p. 12), a intenção que residiu esta ida a campo também foi subsidiada pela necessidade de entendimento dos regimes de verdade - também uma noção foucaultiana - que engendraram e regularam a produção de discursos que supostamente seriam manifestos na entrevista, de forma que, uma incursão no pensamento do filósofo garantiu "o entendimento dos discursos proferidos pelas professoras e professores investigadas/os enquanto resultantes de relações de poder constituídos em um tempo que não é o nosso".

Nesse sentido, não foi preocupação desta investigação que ora se apresenta a delimitação de vertentes específicas ou identificação de modalidades em EA que compõem o multifacetado território brasileiro nem mesmo dar uma nova adjetivação que passaria a compor as modalidades de EA existentes, mas sim indagar, como propõe Guimarães (2003, p. 335) "sobre os princípios básicos norteadores dessas inúmeras ações", perguntando, nessa direção, "quais seriam os enfoques culturais, políticos, pedagógicos e epistemológico-sociais que poderiam estar atravessando-as". Pensar uma EA pós-moderna estaria, assim, muito mais próximo de reconhecer o caráter contingente que atravessa seus potenciais campos de ação sempre particulares, abrindo mão de fixar certos contextos previamente delineados, como se aguardassem, estáticos, serem "capturados" por uma malha teórica lançada sobre eles.

Desta forma, o interesse aqui reside particularmente na apresentação de alguns recortes discursivos anunciados por professores, recortes estes entendidos não apenas como representativos, mas inextricáveis de determinada episteme que, por sua vez, orientam práticas específicas carregadas de traços históricos, filosóficos e políticos de um tempo. Entendidos em sua materialidade, a importância que se dá aos discursos emitidos por esses sujeitos de pesquisa não se resume ao mero significado daquilo que se diz ou se está por dizer, mas são estes aqui entendidos como elementos que constroem significados e sentidos no momento mesmo em que são anunciados/ reproduzidos, orientando, assim, práticas pedagógicas que contém em seu âmago um entrelaçamento muito particular quando, por exemplo, empregam terminologias como ciência e crise ambiental, forjando direcionamentos em EA orientados por certas relações de poder. O próprio uso e mobilidade que se dá a certos saberes, em detrimento da totalidade possível

\footnotetext{
${ }^{3}$ Alfredo Veiga-Neto (2011) prefere tratar por domínios foucaultianos em vez de fases para evitar a falsa impressão de que a obra de Foucault encontra-se propositalmente dividida pelo autor. Tal terminologia é utilizada somente por uma questão didática.
}

revista brasileira educação ambiental 
de saberes existentes, já é, neste estudo, entendido como uma condição prática, pulverizando a tradicional separação teoria/prática que comumente se faz no grande contingente de pesquisas das ciências da educação.

Espera-se com este texto contribuir para essas novas realidades de propostas investigativas que, aos poucos, vem se descortinando como realidade, multiplicando as facetas de pesquisas em EA que duvidam das supostas neutralidades discursivas que veiculam noções, comportamentos e práticas específicas de se relacionar com o meio ambiente. Ao trazer esses discursos representativos analisados à luz de um problema de pesquisa mais amplo de olhar foucaultiano, busca-se colocar em evidência certas relações forjadas no emparelhamento de camadas discursivas, evidenciar seu campo enunciativo de presença, buscando manter a salvo a suposição de Foucault (2012, p. 21) de que não há sociedade em que não existam narrativas maiores que se contam e se repetem, coisas ditas que se conservam, "porque nelas se imagina haver algo como um segredo ou uma riqueza". moderna

DEVORAÇÕES ${ }^{4}$ : direcionamentos para uma educação ambiental pós-

"A ideia antropofágica não aceita passivamente andar pelos caminhos já cansativamente trilhados. Não anda à procura de mapas seguros feitos com tintas eternas. Antes, pelo contrário, aceita o desafio pós-moderno de fazer o mapa durante o caminho" (BARCELOS, 2004, p. 197-198).

Existe um número cada vez mais significativo de autores que passa a utilizar a terminologia pós-modernidade para se referir ao atual contexto sóciopolítico-cultural como condição dos desdobramentos do pós-guerra. Ainda assim, existe também o clamor daqueles que não concordam com um adentrar definitivo das sociedades modernas e suas formas de pensar para essas outras configurações de sociedades, as pós-modernas, sem que isto esteja isento de problemas.

Nesses direcionamentos que admitem a modernidade como cerne que rege civilizações ainda em vigor, tende-se a adotar outras terminologias que pulverizam essa suposta transição cristalina, admitindo em alguns casos, que tenha existindo agravamentos e desdobramentos da própria modernidade. A título de ilustração de alguns desses títulos, tem-se modernidade tardia ou modernidade reflexiva (GIDDENS, 1991), modernidade líquida (BAUMAN,

\footnotetext{
${ }^{4}$ Provocação dos autores Valdo Barcelos e Ivete Silva (2007, p. 145), o termo aqui é utilizado no sentido de uma inclinação favorável e necessária ao estatuto da EA antropofágica, isto é, aquela que visa se distanciar das "amarras das fórmulas e das metodologias tradicionais de pesquisa/ensinar/aprender", as quais acabam por orientar práticas que mais copiam do que inventam. A incorporação de elementos provenientes do manifesto antropofágico para que se pense essa independência também é encontrada em Reigota (2002).
}

Revbea, São Paulo, V. 12, № 4: 165-179, 2017. 
2001; 2007) e hipermodernidade (LIPOVETSKY, 2004). Apesar desta diversidade terminológica apenas em parte aqui ilustrada, tais autores inclinamse ao reconhecimento de que existe uma "rasura" nas formas de pensar esta modernidade desde o nascimento de seu projeto de sociedade, seja pelo reconhecimento de que suas orientações não mais têm validade em uma realidade dinâmica e acelerada, seja pelo reconhecimento de que certas promessas sequer foram outrora consagradas.

Neste estudo, contudo, optou-se pela manutenção da noção de pósmodernidade - admitida em seu escopo mais amplo desta investigação visando dar substância ao modo com que inúmeros outros estudiosos brasileiros vêm tratando; à exemplo, Reigota (2002). Esta plêiade, contudo, também não está isenta de heterogeneidade. Existem investigações que reconhecem a necessidade de mudanças teóricas, paradigmas metodológicos e diferentes olhares para 0 mundo em que a EA, em suas diferentes modalidades, é exercida antes mesmo dessas transições paradigmáticas; assim como aqueles que reconhecem que a EA figura como elemento posterior a esta condição pós-moderna, isto é, como exigência desta.

Marcos Reigota (2010, p. 42) defende a necessidade de a América Latina redefinir seu modelo de desenvolvimento nesta virada de milênio, que passa a ser configurada por mudanças na conjuntura política, econômica e ecológica mundial; neste cenário a "educação ambiental situa-se como um dos elementos da pós-modernidade". Para este estudioso, um dos pontos em comum das tendências da ecologia contemporânea é a crítica ferrenha à modernidade. Esta, por sua vez, é aqui entendida como um estilo de vida que gestou a cristalização de inúmeras representações de ordem binária, em que os elementos da natureza aparecem em dimensão oposta à cultura característica do mundo humano, elementos que garantiram uma ampla circulação de discursos em nossa cultura, que se consagra ainda de maneira "pavimentada" sob os moldes modernos. Este estado de cultura que também pode ser referido como uma "cosmovisão moderna" sustentada num projeto iluminista (COSTA, 2005) detém de forma característica uma base:

[...] assentada sobre noções clássicas de verdade (universal/transcendental), razão (universal), identidade (centrada, una, estável) e objetividade, sobre as ideias de progresso e emancipação, e sobre as grandes narrativas fundadoras com seus sistemas totalizantes e explicações generalizáveis e definitivas. De acordo com muitos filósofos e críticos da cultura, o mundo dito pós-moderno e os movimentos, filosofias e vertentes de pensamento que se esboçam nele, estilhaçam esta visão moderna e tendem a conceber o mundo como contingente, gratuito, disperso, instável, diverso e imprevisível (COSTA, 2001, p. 2010). 
O reconhecimento da necessidade de libertação desses parâmetros clássicos contribuiria, na visão de Reigota (2010), para um papel estratégico garantido pela EA, o que possibilitaria e buscaria no plano educacional e pedagógico "a desconstrução de clichês e slogans simplistas sobre as questões ambientais e a construção de um conhecimento mínimo (ou representações sociais qualitativamente "melhores", na linha teórica seguida por ele) sobre temas complexos e desafiadores de nossa época" (REIGOTA, 2002, p. 83). O autor se refere à complexidade política, cultural, social, econômica e, também ecológica que eclodiu ao final do século $X X$, o que redefiniu e vem redefinindo as exigências educativas que sejam capazes de fazer frente a essas mudanças.

Os ideários educacionais baseados no lluminismo e no modernismo, anteriores portanto às bombas atômicas lançadas em Hiroshima e Nagasaki, embora continuem válidos em algumas situações, não podem mais ser considerados como únicas referências dos processos pedagógicos. É nesse contexto pós-iluminismo, pós-bomba atômica, pós-modernista que a práxis educativa precisa se situar (REIGOTA, 2002, p. 139).

$\mathrm{Na}$ esteira desse contexto do pós-guerra, Barcelos e Silva (2007) criticam a grande parte da produção intelectual em EA contemporânea inspirados no manifesto antropofágico oswaldiano. Ainda prisioneira de servilismos, os autores concordam com a necessidade de que nossas produções devam ser capazes de superar a manutenção de modismos de pesquisa, que por medo dos riscos e perigos da criação optam pela preguiça da imitação. Oswald de Andrade, relido pelos autores, anunciava para a necessidade de abrir-se ao estranho, ao estrangeiro e ao desconhecido. Nesse sentido, apresenta-se a seguir, o caminho metodológico trilhado nesta investigação. Longe de previamente esboçado, o arcabouço metodológico foi construído durante o trajeto.

\section{Metodologia}

A pretensão diante desse percurso investigativo foi a de contribuir para o campo de investigações em EA buscando conhecer quais discursos são anunciados por esses professores a respeito de ciência, crise ambiental, e que formações discursivas são movimentadas na interface de tais saberes, de que maneiras estes norteiam ou mesmo determinam as abordagens pedagógicas diante do que se convencionou chamar de crise ambiental e que potenciais práticas em EA assumiriam em sala abordando tal questão (se abordam) foram alguns dos objetivos deste trabalho. A preocupação central durante 0 desenvolvimento desta pesquisa foi a de 'escavar' verticalmente as camadas dos discursos encontrados buscando possíveis condições as quais estão 
submetidos, identificando elementos de uma repartição - "objetos, modalidade de enunciação, conceitos, escolhas temáticas", ou, ainda, "condições de existência em uma dada repartição discursiva” (FOUCAULT, 2013, p. 47).

Para atender a essa demanda adotou-se a entrevista de tipo estruturada como instrumento de coleta, uma vez que fora seguido um roteiro abordando pessoas selecionadas de acordo com um plano (MARCONI; LAKATOS, 2010, p. 180). As questões foram mantidas a todos os sujeitos de pesquisa de forma que não houvesse adaptação a novas perguntas de acordo com diferentes entrevistas, uma vez que a análise teve como eixo organizacional as formações discursivas.

Todas as entrevistas foram audiogravadas e transcritas para possibilitar uma organização do conjunto de enunciados nas falas dos professores. $O$ questionário que orientou a entrevista foi composto por oito questões, sendo que os elementos trazidos nesse estudo são decorrentes somente à segunda metade das questões que compuseram a entrevista. São as seguintes: "O que você compreende por crise ambiental?", "Como você situa a posição de ciência em meio à crise ambiental?", "O que você poderia fazer com relação à crise, na posição de professor de Ciências?" e, finalmente, "Supomos que em suas aulas você tivesse a necessidade de tratar da problemática ambiental atual. Como você abordaria tal questão?".

Por meio do conceito de formação discursiva ${ }^{5}$ (Foucault, 2013), o corpus de análise foi dividido no que se convencionou chamar por focos. Os Focos 1, 2 e 3 contemplaram as respostas das primeiras questões, relativas aos enunciados sobre ciência. A análise, contudo, só pode ser separada de maneira didática, uma vez que o que compôs os Focos A e B que detiveram conteúdo das questões apresentadas acima tem considerável envolvimento com as compreensões que se faz de ciência. Desta forma, os enunciados aqui apresentados não estão "pinçados" de forma aleatória, mas compõem blocos de análises, de saberes ocidentais que caracterizam a noção de episteme em Foucault (2007).

Por meio deste trajeto metodológico buscou-se fugir de explicações de ordem mecanicista, cedendo terreno para outros modos de explicar de que possíveis modos nos tornamos sujeitos de certos discursos e por meio de quais as separações, distinções e atribuições históricas, certas verdades se tornam naturalizadas.

DEGLUTIÇÕES e REGURGITAÇÕES ${ }^{6}$ : movimentações e resistências discursivas na entrada do terceiro milênio

\footnotetext{
${ }^{5}$ Formação discursiva, tal como aparece em 'A arqueologia do saber', é designada como "um conjunto de enunciados que se apoia em um mesmo sistema de formação" (FOUCAULT, 2013, p. 128).

6 Seguindo à metáfora oswaldiana, o movimento que vem após uma devoração é o de deglutição. É o ato ou efeito de engolir. Regurgitar é vomitar, expulsar aquilo que está em excesso. Também tomados de empréstimo das investigações empreendidas por Barcelos 
Neste ponto, trazem-se os discursos em certa organização a fim de analisar que potenciais efeitos estes movimentam de acordo com a trajetória de questões delineada. Apresenta-se de início os dois focos distintos, identificados pelo crivo analítico das formações discursivas deste segundo conjunto de questões analisadas. Deles, notaram-se dois direcionamentos nitidamente distintos:

- Foco A - Crise ambiental entendida como um desequilíbrio de ecossistemas e interrupção de ciclos naturais: apoiam-se em tais formações enunciados que correspondem ao ambiente em sentido naturalista, direcionando-se a discursos de ordem reificada, como poluições das águas, do ar e solo e o desmatamento, por exemplo. Frequentemente associado à ecologia natural, a questão ambiental nestas formações discursivas restringem-se a abordagens técnicoinstrumentais das quais é possível emergir soluções para a crise mediadas pela própria ciência. Situam-se aqui os enunciados expressos pelos professores P1, P2, P4, P5, P6, P7 e P8.

- Foco B - Crise ambiental entendida como resultado de uma relação ser humano-natureza mediada por uma operacionalidade técnicocientífica: a compreensão de ciência que se fez na primeira parte deste estudo permitiu com que se estabelecessem questionamentos sobre a hegemonia da racionalidade técnico-instrumental. Situam-se aqui os enunciados expressos pelos professores P3 e P9, apenas.

Uma primeira consideração após o contato com os ditos manifestados foi o modo com que esses elementos surtiram posições inesperadas no emparelhamento de enunciados: por mais que a maior parte das compreensões de ciência tivesse figurado como cedidas aos desacomodares pós-modernos (representadas pela formação dos Focos 2 e 3, não trazidos nesta análise), a mesma situação não ocorreu no delineamento das práticas anunciadas, que sugeriram posições ainda refratárias a esses desacomodares, caracterizando uma estridência entre o que se compreende e o que, de fato, se pratica. É como se, à medida que houvesse uma complexidade de temas, como o acrescentar da crise ambiental nesta equação, desacomodasse essas compreensões abertas de ciência, evocando discursos característicos da modernidade.

Até mesmo as respostas de P3 e P9 - que foram circunscritas em um foco à parte devido ao distanciamento de enunciados - mantiveram proximidade

(2004). O sentido conotativo aqui empregado faz alusão ao movimento de aceitação/rejeição, na respectiva ordem, dos professores de Ciências para com os elementos da linguagem, escopo mais amplo desta pesquisa. Nesta mudança de episteme, o que estes aceitam e o que recusam? O que escolhem movimentar em termos discursivos ao longo de sua prática e o que decalcam, minam e silenciam no fluir das práticas e das trocas? O que engolem e, enfim, regurgitam?

Revbea, São Paulo, V. 12, № 4: 165-179, 2017. 
quando manifestados os posicionamentos pedagógicos, indicando que, apesar de haver compreensões de crise ambiental como resultado de uma relação ser humano-natureza, a qual é mediada por uma operacionalidade técnicocientífica, este reconhecimento não implica no domínio pedagógico, favorecendo a manifestação de práticas que fortalecem discursos hegemônicos. É como se fossem "verbetes" isolados, que atendessem a um tipo de exigência discursiva exigida pela sociedade, são discursos eleitos que se consagram quando manifestos de forma individualizada, mas que, mediante a circulação que compõe outros elementos, pudessem ser decifrados em sua construção aparentemente bem-intencionada.

"Cortando em partes" esses discursos, essa compreensão de uma relação reificada ser humano-ambiente aparece caracterizada nos enunciados manifestos nas compreensões de crise ambiental, anunciadas pelos professores integrantes do Foco A, que foram os seguintes: "a perda da biodiversidade", manifestada por P1; um "colapso ecológico", referindo-se a um desequilíbrio do meio ambiente, manifestado por P2; "a degradação do ambiente", que se desdobra em uma somatória de fatores como a "poluição do solo", a "poluição da água" e a "poluição do ar", manifestado por P4; "à falta de consciência dos sujeitos", que leva a consecutivas ações como jogar lixos nos bueiros, manifestado pelo sujeito P5; ao "uso inoportuno e quantidade inadequada" dos elementos do meio ambiente, o que desencadeou num suposto "descontrole do ciclo", resultado da adoção de atitudes "antrópicas", manifestado por P6; "a interferência do homem na natureza", exemplificada por fatores como "desmatamento, retirada de substâncias do solo, aumento de populações e a poluição que é jogada no ar", manifestado por P7; e, por fim, as alterações climáticas causadas pela poluição e 0 uso de agrotóxicos caracterizam-na para o sujeito $\mathbf{P 8}$.

Identificou-se que tais formações discursivas se aproximam da concepção ecologista identificada por Sousa (2011, p. 40) em que a ênfase "é pautada na conservação da natureza por si, para que se evitem os desequilíbrios. Para os defensores dessa proposta, o ser humano sempre polui o ambiente, sendo o único responsável pelos desastres ambientais da atualidade". Essa visão supõe um forte apelo a uma natureza primitiva ou primeira natureza, uma natureza isenta de cultura.

Concorda-se que a este primeiro foco existe todo um campo associado de discursos que facilmente caíram em verbetes típicos do pensamento moderno. Operando pelo antagonismo equilíbrio/desequilíbrio, a crise ambiental é característica, por meio desses enunciados, do desequilíbrio de uma noção de "ordem" entre elementos da natureza que poderiam voltar ao seu estado natural por meio da intervenção científico-tecnológica. A dualidade mantida por esses discursos impede que sejam pensadas situações mais complexas em que a ciência assuma potencial efeito negativo sobre as formas de se viver no ocidente.

Arqueologicamente investigando, identifica-se que tais dicotomias homem/natureza e natureza/cultura - são herdadas da filosofia cartesiana que

revista brasileira educação ambiental 
situa o ser humano elemento nefasto a esta ordem natural (uma vez que não pertence a ela) sem que se leve em conta seus aspectos contingentes e históricos, seus recortes de classe, cultura e estilos de se viver em sociedade etc. É evidente que os aspectos naturais são, sim, legítimos, devendo ser pauta nas reuniões de Fóruns e Conferências nacionais e globais, mas não se pode cair no reducionismo discursivo de que representam toda a questão ambiental naturalizando tal questão e esquecendo-se das relações de poder que a ela estão inerentes, garantindo o vigor de certos interesses.

Esta reificação da questão ambiental está inextricavelmente ligada à manifestação de alguns enunciados que atribuem uma ou mais posições à ciência no contexto de crise ambiental, como se escolheu aqui representar pela seleção dos casos de P1, P2 e P4:

[...] a ciência é uma ferramenta pra eu trabalhar com a crise ambiental. Eu acho que utilizando os métodos científicos conhecidos a gente pode chegar a eventuais soluções 'né', e soluções que podem ser muito interessantes pra problemas tanto de cunho social quanto de cunho ambiental [...] (P1) grifo nosso.

\section{A princípio dando veracidade ou não a essa crise... Depois sugerindo formas de voltá-la ao equilíbrio, e o tempo todo monitorando [...] (P2) grifo nosso.}

A ciência ela precisa é [...] prover soluções. Buscar soluções pra solucionar a crise ambiental. Então ela 'tá' na posição de... de solucionar, de buscar respostas. Meios pra é... diminuir, e se for o caso, eliminar, não eliminar não... reverter na medida do possível a crise [...] (P4) grifo nosso.

Novamente, sob um crivo arqueológico, localiza-se a gestação de tais discursos nos entremeios da cisão propiciada pelas influências de Francis Bacon e Renée Descartes, cujos princípios pautaram-se na conversão de uma natureza orgânica em mecânica, na leitura de um mundo como um mundo máquina, regido pelo olhar mecanicista. Este ambiente, situando-se como objeto na cisão sujeito-objeto, aguarda de maneira passiva a intervenção humana.

O íntimo entrelaçamento entre essas ideias garante um "respingar" na prática pedagógica, orientada por enunciados característicos, como: práticas de sensibilização, a promoção de feiras, exposições e outros eventos no colégio em que lecionam que levassem em conta práticas de reciclagem e outras abordagens pontuais como um dia da bicicleta, em que os alunos que vão de bicicleta à escola e, ao fazer isso, ganhariam um desconto no lanche (P1). A informação levada aos alunos como elemento para correção da crise é a resposta de P2. A influência do professor nas atitudes dos alunos, algo que sugere uma postura próxima de uma "pedagogia do exemplo", aproximam as posições de P4 e P5, exemplificado na tomada de decisões como se policiar 
para não jogar lixo no chão (P4) ou mesmo pegar o papel do chão quando este foi atirado pelos próprios alunos (P5). P5 ainda manifestou preocupações com relação ao desperdício das folhas de caderno, orientando para esses casos, o máximo de utilização possível das linhas de cada folha. P7 e P8 manifestaram, ainda, a possibilidade no ensino de Ciências, de "reverter" comportamentos e conscientizar os alunos perante a sociedade e ao ambiente.

Tais manifestações são incapazes de contemplar o caráter diaspórico que sustenta a maioria das sociedades ocidentais, isentas de territórios homogêneos sem a agregação de jogos de interesse, do qual faz parte a ciência. Neste ínterim, contemplam muito pouco os discursos que se direcionam ao reconhecimento de que a ciência só manifesta efeitos no interior e em relação a outros elementos de um campo discursivo. As manifestações discursivas características do primeiro foco apresentado estão, nesse sentido, distantes de uma visão de ciência orientada, por exemplo, pelo fatídico episódio do uso das bombas atômicas em Hiroshima e Nagasaki.

De forma oposta, as formações discursivas das quais se orientam os discursos que compõem o Foco 2 reconhecem este atravessamento. Ao discorrer sua compreensão de crise ambiental, os professores P3 e P9 manifestaram, também, uma estreita relação entre o conhecimento técnico proveniente dos saberes científicos e, por isso, parecem questioná-los na maneira com que estão atualmente empregados. Apoiam-se, nesse sentido, em uma formação discursiva que atribui caráter de problema à substituição das questões políticas e éticas que vão além do apelo técnico-científico:

Eu acho que o homem nessa ambição que a gente tem de sempre "tá" querendo tirar proveito [...] às vezes a gente não toma consciência [...] só quer saber de lucro, não toma consciência de que "tá" danificando, prejudicando e manipulando, fazendo tudo de acordo com o que os nossos interesses convém [...] "A gente" coloca muitas vezes o nome da ciência, usa "né", como desculpa pra fazer estudos e na verdade é tudo interesse que "a gente" tem [...] (P3 grifo nosso).

Nós começamos com esses problemas há bastante tempo. Eu sempre me lembro do buraco [...] onde nós começamos a desenvolver tecnologias, usando gás que a gente não conhecia direito. Inicia assim: qual o objetivo desse gás? O objetivo é refrigerar, então vamos fazer geladeiras, freezers, ar condicionado... Sem nos preocupar qual ocorrência, qual consequência iria ter deste tal fato e daí tantos anos depois começamos a verificar os efeitos a esse gás CFC. E aí o que a gente teve que fazer? Achar alternativas... é aí que gera toda a crise. Parece que primeiro a gente destrói pra depois construir. E aí vem desde Maringá, 67 anos atrás era uma floresta, vamos dizer assim, hoje é uma floresta de concreto. Mato Grosso do Sul era a floresta Rondônia, hoje são imensas 
plantações de soja pra fazer ração para os gados confinados da Europa e o nosso pessoal aqui não tem comida, não tem como buscar essa comida. Então, porque não planta grandes lavouras de tomate, que não seja com tanto agrotóxico. Porque não trigo, "pro" povo fazer pão? Porque criar tanto boi pra exportação, se quando eu vou comprar o boi meu é de péssima qualidade e o boi que vai pra fora é de melhor qualidade? Nós moramos num país tropical, não precisaria de tanta genética, vamos falar assim. Claro que é legal se tem melhoramentos, mas pra nós aqui já é suficiente, só nosso solo já produz muito alimento, muitas frutas, muitas verduras e só ali já tem os nutrientes necessários. E quando eu vou comprar uma maçã, uma banana, uma manga, eu compro de pior qualidade. Se eu quiser um café decente eu tenho que ir 'pros' Estados Unidos, com a minha mãe, tomar um café, porque o que fica pra nós é o resto do resto. Então essa "dissociedade" que a gente vive, esse consumismo, essa ganância, acaba afetando a gente o tempo todo e acaba afetando isso, aí vem essa crise ambiental. Então porque eu "to" indo plantar soja? Pra exportar! Porque a gente tem que ter um monte de boi pisoteando, destruindo? Pra exportar! Bom então o que fica pra nós? Então pra mim isso é uma grande crise ambiental (P9 grifo nosso).

Os exemplos dados pelos docentes parecem assumir a posição de denúncia diante de uma suposta neutralidade das escolhas técnico-científicas que perpetuam um capitalismo predatório como nos casos em que milhares de hectares de nossos biomas são transformados em pastos com a finalidade exclusiva de exportação de gado de corte. Ao colocar tais questões em circulação, este sujeito do enunciado acima se encontra menos refratário diante do declínio das propostas do projeto de modernidade; reconhece que muitas promessas não se consagraram e que a fome não fora eliminada com o advento da tecnologia; que não bastou que o melhoramento genético fosse desenvolvido para que graves conflitos alimentares fossem solucionados. Temse, nessas formações discursivas, um abandono da noção de objetividade das ideias de progresso e emancipação. P3 e P9 contestam que emancipação é esta, característica dessas relações citadas, decorrentes da atual conjuntura.

Também anunciados por eles, a operacionalidade sem planejamentos que se realiza por meio de experimentações sem que se tenha o total controle de como algumas atitudes afetarão a vida no futuro - testamos primeiro, verificamos depois, como é o caso do gás CFC - está pareada com os aspectos contingentes do uso da ciência, fazendo sentido à luz de realidades muito particulares, em determinadas situações. Tem-se aí, também, um rompimento com a razão universal instituída na modernidade. Tais enunciados colocam à prova o binômio ética-técnica, caracterizando outras condutas docentes frente à crise ambiental. 
Nas abordagens pedagógicas, contudo, como expresso no início dos resultados, esses mesmos sujeitos que atribuem caráter de problema para esta racionalidade técnico-instrumental acabam por manifestar discursos hegemônicos caracterizados pela noção salvacionista dos saberes técnicos, implicando no ocultamento de decisões políticas.

No âmbito das abordagens pedagógicas e posturas como professores de ciências os professores entrevistados continuam por manter um pensamento instrumental, o que está intimamente relacionado à dificuldade existente de que novas práticas pedagógicas transcendam o plano meramente técnico. Esta pretensa seleção de enunciados que demarca, de forma consecutiva, uma especificidade na relação Ser-Saber é que orienta as práticas em EA. A verdade técnico-científica característica do pensamento instrumental identificada neste caso continua mote das práticas que foram narradas quando questionados o que é possível fazer em relação à crise na posição de professor/a de Ciências e possíveis abordagens em suas aulas.

Notou-se, pelo emparelhamento de questões que orientaram esta investigação, que apesar de haver compreensões de crise ambiental como resultado de uma relação ser humano-natureza mediada por uma operacionalidade técnico-científica, o mesmo não ocorre no domínio pedagógico, preservando práticas que fortalecem discursos hegemônicos. É como se nas abordagens em sala de aula praticamente não houvesse um domínio na relação ser-saber suficiente para que se renovassem e reformulassem essa perspectiva discursiva em que se entende que a educação muda a sociedade e predomina-se a máxima "conhecer para preservar".

\section{Considerações finais}

Esta investigação se dispôs a pensar quais conteúdos discursivos são reverberados pelos professores em detrimento a conteúdos rarefeitos, à luz de uma análise arqueológica foucaultiana. Ao optar por este domínio, contudo, esgota-se em demarcações arqueológicas, que contribuem para que se conheçam condições históricas que agiram em consonância para que determinadas práticas fossem geridas. Desta forma, não estão contempladas, em sua totalidade, um estudo mais aprofundado das relações de poder, mesmo que essas apareçam de forma inerente na própria seleção dos enunciados manifestos. Acredita-se que para que se chegue mais próximo de problematizações mais consistentes e completas, fazem-se necessárias futuras investigações que se detenham à análise das relações de poder, levando em conta o método genealógico, buscando minar, nesses próximos trabalhos, que relações estiveram em vigor para que essas séries de discursos se estabelecessem; com o apoio de quais sistemas de coerção; com que normas específicas, condições de aparição, crescimento e variação - uma vez que, sob o pensamento do filósofo, saber e poder são elementos indissociáveis.

O recorte dos estudos mostrou que ainda não há consenso sobre o que aqui foi entendido por pós-modernidade, mas também evidenciou que esta

revista brasileira educação ambiental 
pode ser definida como uma sociedade que tem mudado e provocado revoluções sociais e culturais, assim como científicas. Ainda assim, os discursos que expressam esse reconhecimento aparecem em uma lenta inflexão. O domínio arqueológico - no sentido de raspar, escavar o que está embaixo das primeiras camadas -, permitiu visibilizar uma tímida e ainda muito precária visão de ciência e história, ciência e política e das relações ser-saber. Os poucos enunciados que fraturam esta ordem hegemônica da posição de ciência em meio à crise, obliteram-se quando são pensados diante de elementos mais complexos, como de que modo seriam expressos em práticas pedagógicas.

Admitiu-se, portanto, que apesar de uma nova constelação de saberes ter surgido diante da inflexão de milênio e, de forma particular para este estudo, da expectativa de resolução da crise ambiental, é como se os docentes estivessem dizendo "verdades" apesar de seu tempo. Não se considera, nesse âmbito, que os enunciados provenientes de Bacon e Descartes estejam errados, mas que são históricos e, portanto, contingentes. A manutenção deles em nossos tempos expressa relações íntimas com certas tentativas de manutenção de um desenvolvimento econômico que não corresponde à totalidade desses tempos e a maneira com que vem expressa, bem como as razões pelas quais insistem em continuar a aparecer necessita de futuras investigações.

\section{Referências}

BARCELOS, V. Educação Ambiental e formação de professores(as): contribuições filosóficas da antropofagia cultural. in. BARCELOS, Valdo; ZAKRZEVSKI, Sônia Balvedi (Orgs.) Educação ambiental e compromisso social: Pensamentos e Ações. Erechim, Rio Grande do Sul: EdiFAPES, 2004.

BARCELOS, V. SILVA, I.S. Saberes, sabores e devorações: para uma educação ambiental antropofágica e pós-moderna. In. PREVE, A.M.; CORRÊA, G. (Orgs.) Ambientes da ecologia: perspectivas em política e educação. Santa Maria: Editora da UFSM, 2007.

BAUMAN, Z. Modernidade líquida. Rio de Janeiro: Zahar, 2001

BAUMAN, Z. Tempos líquidos. Rio de Janeiro: Zahar, 2007.

COSTA, M.V. Velhos temas, novos problemas: a arte de perguntar em tempos pós-modernos. In. COSTA, M.V.; BUJES, M.I. (Orgs.). Caminhos investigativos III: riscos e possibilidades de pesquisar nas fronteiras. Rio de Janeiro: DP\&A, 2005.

FOUCAULT, M. As palavras e as coisas: uma arqueologia das ciências humanas. 9aㅡ. ed. São Paulo: Martins Fontes, 2007.

FOUCAULT, M. A ordem do discurso. 22 ed. São Paulo: Edições Loyola, 2012. 
FOUCAULT, M. A arqueologia do saber. 8. ed. Rio de Janeiro: Forense Universitária, 2013.

GIDDENS, A. As consequências da modernidade. São Paulo: Editora Unesp, 1991.

GUIMARÃES, L.B. O educativo-ambiental construído sob o binarismo natureza/cultura nos limiares do terceiro milênio. In. NOAL, F.O.; BARCELOS, V.H.L. (Orgs.) Educação ambiental e cidadania: cenários brasileiros. Santa Cruz do Sul: EDUNISC, 2003.

LIPOVETSKY, G. Os tempos hipermodernos. São Paulo: Editora Barcarolla, 2004.

MALDONADO, M.M.C. A ordem do discurso da educação ambiental. Dissertação (mestrado). Porto Alegre: UFRGS, 2001.

MARCONI, M.A.; LAKATOS, E.M. Fundamentos de metodologia científica. 7. ed. São Paulo: Atlas, 2010.

REIGOTA, M. Educação ambiental: fragmentos de sua história no Brasil. In. BARCELOS, V.H.L.; NOAL, F.O.; REIGOTA, M. (Orgs.) Tendências da Educação Ambiental Brasileira. Santa Cruz do Sul: EDUNISC, 1998.

REIGOTA, M. Meio ambiente e representação social. 8. ed. São Paulo: Cortez, 2010.

REIGOTA, M. A floresta e a escola: por uma educação ambiental pósmoderna. 3. ed. São Paulo: Cortez, 2002.

SOUZA, C.E.P. Reflexões sobre Educação Ambiental: subsídios para a formação de educadores. In. ARRUDA, V.L.V.; HANAZAKI, N. (org.). Tecendo reflexões em educação e meio ambiente. Florianópolis: Ed. da UFSC, 2011. 